\title{
Passive Smoking, Pulmonary Function and Bronchial Hyper-responsiveness among Indoor Sanitary Workers
}

\author{
Ayamn Ekram FAHIM ${ }^{1 *}$ and Mahmoud EL-PRINCE ${ }^{2}$ \\ ${ }^{1}$ Community Medicine Department, Occupational Health Group, Faculty of Medicine, Suez Canal University, \\ Egypt \\ ${ }^{2}$ Pulmonary Medicine Unit, Faculty of Medicine, Suez Canal University, Egypt
}

Received March 8, 2012 and accepted July 18, 2012

Published online in J-STAGE October 8, 2012

\begin{abstract}
Pulmonary function parameters of 21 cleaning/sanitary women workers who have never smoked, exposed to environmental tobacco smoke (ETS) at work were compared with 34 non-exposed women workers of comparable age and other work characteristics. The studied subjects were subjected to an interview questionnaire, pulmonary function measurements, bronchial responsiveness assessment and clinical chest examination. A higher prevalence of dyspnea was found $(\mathbf{4 2 . 9 \% )}$ among exposed compared to $(14.7 \%)$ among the non-exposed workers $(p=0.019)$, also wheezing (52.4\% vs. $11.8 \%$; $\mathrm{p}=0.001)$. Pulmonary measurements showed a lower $\mathrm{FVC}, \mathrm{FEV} / \mathrm{FVC}_{1}$ and $\mathrm{FEF}_{75}$ values among exposed compared to non-exposed $(\mathbf{p}<0.05)$, and a higher prevalence of borderline bronchial hyper-responsiveness $(38.1 \%$ vs. $11.8 \%$; $p=0.021)$ in the exposed workers. This study provides evidence of adverse respiratory effects in sanitary/cleaning women workers associated with passive smoking in the workplace. The findings support a stricter implementation measures to protect respiratory health of all workers.
\end{abstract}

Key words: Environmental tobacco smoke, Respiratory function, Bronchial hyper-responsiveness

\section{Introduction}

Cleaning and sanitary workers are potentially exposed to a number of sensitizers and irritants, with consequent adverse respiratory effects ${ }^{1}$.

Workplace exposures are responsible for $5-20 \%$ of adulthood asthma ${ }^{2)}$. Several studies have shown an increased risk of lung function impairment and asthma in household and professional cleaning workers ${ }^{3}$. Studies have shown that exposure to environmental tobacco smoke

*To whom correspondence should be addressed. E-mail: afahim70@gmail.com

C2012 National Institute of Occupational Safety and Health
(ETS), also referred to as passive smoking and secondhand smoking, increases the risk of asthma and respiratory symptoms in exposed workers ${ }^{4}$. ETS is a mixture of sidestream smoke and exhaled mainstream smoke containing the same substances as mainstream smoke inhaled by smokers. Several studies have indicated that exposure to ETS in adults results in a significant impairment of the lung function parameters ${ }^{5}$.

Exposure to ETS is associated with many indoor environments such as home, workplace, public places, and transportation. The magnitude of exposure depends on the number of smokers, the amount smoked, place size and ventilation, and duration of exposure ${ }^{6}$.

ETS exposure can be assessed by measuring air nicotine and respirable suspended particle concentration or by mea- 
suring cotinine (a nicotine metabolite specific for tobacco) in body fluids. In health effects studies, ETS exposure is usually assessed using questionnaires, because they are relatively cheap and allow exposure assessment during different time periods and in different indoor environments ${ }^{7}$.

Bronchial hyper-responsiveness (BHR) refers to an exaggerated response to a bronchoconstrictor. Bronchoconstrictors include pharmacological agents, aerosols, cold air, exercise, allergens and occupational sensitizers. Several epidemiological studies support the view that workplace exposure to air pollutants is associated with a broad spectrum of adverse respiratory effects in vulnerable individuals and the role of occupational exposure (e.g. to mineral or organic dust, gases, fumes, and vapors) in BHR development ${ }^{8)}$.

The present study assessed respiratory effects of passive smoking on lung function, and bronchial responsiveness in sanitary/cleaning women workers, who work indoor where no legal or formal enforcement is implemented.

\section{Subjects and Methods}

This survey was conducted at the administrative buildings of Suez Canal University of Ismailia governorate in 2011. Fifty five female workers (never smoked) aged 24-56 yrs, working as cleaning/sanitary workers with employment duration ranging from 4-27 yrs were included. All study participants lived in Ismailia city with no potential exposure from travelling to or from work.

An informed consent was taken from each participant before introducing the questionnaire; confidentiality and anonymity were maintained according to the regulations mandated by Research Ethics Committee of faculty of medicine Suez Canal University, in accordance with the Declaration of Helsinki.

Among the studied workers, work tasks included dusting, washing, cleaning surfaces, and disposing of waste. Occupational exposure included several types of cleaning products such as soaps and detergents, disinfectants, solvents, and polishes; some of which were in spray form. The cleaning women did not use any personal protective equipment (PPE). The work shift lasts 4-6 hours daily.

According to the European Community Respiratory Health Survey ${ }^{9)}$, study participants were divided into two categories, the first category representing ETS-exposed group which comprise those workers who reported to have at least one smoker in the room, and the second category (non-exposed group to ETS) were women workers who had not been exposed to ETS. Workers who reported to have at home exposure to smoking were not included in the study.

An interview questionnaire included items about sociodemographic, current work characteristics, respiratory symptoms during the previous 12 mon, allergic profile (nasal, eye and skin), and questions on current and previous occupations ${ }^{9)}$.

Pulmonary function measurements of all workers were taken using spirometry Flowhandy ZAN100 USB (ZAN Messgerate $\mathrm{GmbH}$, Germany) and included [FVC], [FEV 1 , [FEV $1 / \mathrm{FVC}$ ratio], [ $\left.\mathrm{FEF}_{50 \%}\right]$, [ $\left.\mathrm{FEF}_{75 \%}\right]$, and $\left[\mathrm{FEF}_{25-75 \%}\right]$. The best of three measurements was recorded and results expressed as percentages of the predicted values, according to the American Thoracic Society (ATS) recommendations ${ }^{10)}$. All respiratory function assessment was done by the same experienced pulmonologist. All measurements were performed at the pulmonary function measurements unit, at mid day between 12-1 PM.

BHR was assessed by histamine challenge [provocative] test according to the American Thoracic Society (ATS) recommendations, different concentrations were prepared, and the studied subjects inhaled increasing concentrations of histamine using a tidal breathing method until $\mathrm{FEV}_{1}$ falls $<20 \%$ of its base value or the highest concentration was reached. According to the ATS recommendations, BHR was categorized into moderate to severe BHR, mild BHR, and borderline BHR ${ }^{11)}$.

All studied subjects were subjected also to chest clinical examination by an experienced pulmonologist with no prior information about the workers exposure status.

SPSS version 13.0 for Windows was used for data management. Comparison between groups was done using Chi-square test for qualitative variables, with $95 \% \mathrm{CI}$ and $t$-test was used for quantitative variables. Results were considered statistically significant if $\mathrm{p}$ value $<0.05$

\section{Results}

Characteristics of the studied subjects are presented in Table1. There is no statistically significant difference between the two groups, as regards age, duration of work, and daily working hours ( $\mathrm{p}>0.05)$.

As presented in (Table 2), the prevalence of dyspnea among ETS-exposed group was higher (42.9\%) compared to the non-exposed group (14.7\%) with statistically significant difference ( $\mathrm{p}=0.019$, OR: 4.4$)$. Chest clinical examination revealed that more than half of the exposed group (52.4\%) had wheezing, and as compared to the nonexposed group (11.8\%) and this showed a statistically 
Table 1. Demographic and occupational characteristics

\begin{tabular}{lccccccc}
\hline \multirow{2}{*}{ Characteristics } & \multicolumn{2}{c}{ Exposed group $(\mathrm{n}=21)$} & & \multicolumn{2}{c}{ Non-exposed group $(\mathrm{n}=34)$} & \\
\cline { 2 - 3 } & Mean & $\mathrm{SD}$ & & Mean & $\mathrm{SD}$ & \\
Age & 38.7 & 7.9 & & 39.3 & 8.5 & 0.489 \\
Duration of employment & 12.4 & 8.6 & & 15.3 & 7.9 & 0.207 \\
Daily working hours & 5.6 & 1.6 & & 6.1 & 1.3 & 0.210 \\
\hline
\end{tabular}

Table 2. Respiratory symptoms and clinical findings among the studied workers

\begin{tabular}{|c|c|c|c|c|c|c|c|}
\hline \multirow{2}{*}{ Symptoms and clinical findings } & \multicolumn{2}{|c|}{ Exposed group $(\mathrm{n}=21)$} & \multicolumn{2}{|c|}{ Non-exposed group $(\mathrm{n}=34)$} & \multirow{2}{*}{ Odds Ratio OR } & \multirow{2}{*}{$95 \% \mathrm{CI}$} & \multirow{2}{*}{$p$-value } \\
\hline & No. & $\%$ & No. & $\%$ & & & \\
\hline Cough & 6 & 28.6 & 5 & 14.7 & 2.3 & $0.61-8.87$ & 0.211 \\
\hline Sputum & 7 & 33.3 & 4 & 11.8 & 3.8 & $0.94-14.94$ & 0.520 \\
\hline Dyspnea & 9 & 42.9 & 5 & 14.7 & 4.4 & $1.21-15.70$ & $0.019 *$ \\
\hline Allergic symptoms (nasal-eye-skin) & 7 & 33.3 & 9 & 26.5 & 1.3 & $0.42-4.54$ & 0.586 \\
\hline Clinical chest findings (wheezing) & 11 & 52.4 & 4 & 11.8 & 8.2 & $2.11-31.81$ & $0.001 *$ \\
\hline
\end{tabular}

*Statistically significant at $p<0.05$.

Table 3. Pulmonary function parameters [PFPs] among the studied workers

\begin{tabular}{|c|c|c|c|c|c|}
\hline \multirow{2}{*}{ PFPs [predicted values] } & \multicolumn{2}{|c|}{ Exposed group $(\mathrm{n}=21)$} & \multicolumn{2}{|c|}{ Non-exposed group $(\mathrm{n}=34)$} & \multirow{2}{*}{$p$-value } \\
\hline & Mean & SD & Mean & SD & \\
\hline $\mathrm{FVC}$ & 90.8 & 10.6 & 96.8 & 10.1 & $0.041^{*}$ \\
\hline $\mathrm{FEV}_{1}$ & 82.8 & 8.9 & 87.1 & 7.6 & 0.062 \\
\hline $\mathrm{FEV}_{1} / \mathrm{FVC}$ & 74.4 & 3.1 & 78.6 & 3.8 & $0.001^{*}$ \\
\hline $\mathrm{FEF}_{50}$ & 62.9 & 9.8 & 65.6 & 11.6 & 0.379 \\
\hline $\mathrm{FEF}_{75}$ & 54.3 & 11.1 & 61.8 & 10.9 & $0.017^{*}$ \\
\hline $\mathrm{FEF}_{25-75}$ & 72.1 & 12.6 & 76.7 & 13.4 & 0.211 \\
\hline
\end{tabular}

*Statistically significant at $p<0.05$.

Table 4. Positive provocative testing [bronchial hyper-responsiveness] and its categories among the studied workers

\begin{tabular}{|c|c|c|c|c|c|}
\hline \multirow{2}{*}{$\begin{array}{l}\text { Bronchial Hyper-Responsiveness } \\
\text { BHR }\end{array}$} & \multicolumn{2}{|c|}{ Exposed group $(\mathrm{n}=21)$} & \multicolumn{2}{|c|}{ Non-exposed group $(n=34)$} & \multirow{2}{*}{$p$-value } \\
\hline & No. & $\%$ & No. & $\%$ & \\
\hline Prevalence & 13 & 61.9 & 9 & 26.5 & $0.009 *$ \\
\hline \multicolumn{6}{|l|}{ BHR categories: } \\
\hline Moderate to severe & 3 & 14.3 & 1 & 2.9 & 0.115 \\
\hline Mild & 2 & 9.5 & 4 & 11.8 & 0.795 \\
\hline Borderline & 8 & 38.1 & 4 & 11.8 & $0.021 *$ \\
\hline
\end{tabular}

*Statistically significant at $p<0.05$.

significant difference between the two groups $(\mathrm{p}=0.001$, OR: 8.2).

Table 3 shows the results of pulmonary function measurements. Exposed group workers had lower mean predicted values as compared with the non-exposed group, with statistically significant difference $(\mathrm{p}<0.05)$ for $[\mathrm{FVC}$ ], [ $\mathrm{FEV}_{1} / \mathrm{FVC}$ ratio], and $\left[\mathrm{FEF}_{75 \%}\right]$.
Prevalence of positive provocation test of BHR was $61.9 \%$ in the exposed subjects, whereas $26.5 \%$ of the nonexposed group workers were positive with statistically significant difference $(\mathrm{p}=0.009)$. As regards the ATS categories of BHR, 38.1\% of ETS-exposed group were positive for borderline BHR, with statistically significant difference $(\mathrm{p}=0.021)$ between the two groups (Table 4$)$. 


\section{Discussion}

The prevalence of passive smoking in the workplace varies between countries, and is related to the prevalence of active smoking and implementation of measures of tobacco control consumption. Indoor workers are potentially exposed to a number chemical compounds that contain, sensitizers and irritants, with consequent adverse respiratory effects ${ }^{1)}$.

Compounds of cleaning products contain chlorine, ammonia, and caustic soda. Mixing these cleaning products may lead to exposure to respiratory sensitizers and irritants. Also, cleaning products contain potentially sensitizing additives like preservatives (Isothiozolinones), corrosion inhibitors (Ethanolamines), and biocides (Quaternary ammonium compounds) ${ }^{12)}$.

Several studies have shown adverse respiratory effects at workplace in cleaning women and found a higher risk of mite sensitization among cleaners, especially in households ${ }^{13-15)}$. In the present study we found a significantly higher prevalence of dyspnea (about 50\%) and positive chest findings [wheeze] among those exposed workers to ETS as compared to the non-exposed group. These findings are $\mathrm{s}$ in agreement with the study of Spanish indoor cleaners conducted by Zock et al. ${ }^{13)}$, who stated that workrelated respiratory symptoms were reported by more than a half of the subjects.

Ho et al. ${ }^{16)}$ demonstrated an association between respiratory symptoms and passive smoking both crosssectionally and prospectively after a two-year follow-up.

In a study which investigated the relation between respiratory symptoms and ETS exposure at work and at home in never-smoking Italian women, Simoni et al. ${ }^{17)}$ found that ETS exposure, especially at work, was significantly associated with respiratory symptoms. Similarly, in the study of police officers in Hong Kong, Lam et al. ${ }^{18)}$ reported a significant association between respiratory symptoms and passive smoking in the workplace which was dose-related. Both are in agreement with the findings of the present study.

We found a difference between exposed and nonexposed groups to ETS of some parameters of pulmonary function. This difference was statistically significant for significant for $\mathrm{FVC}, \mathrm{FEV}_{1} / \mathrm{FVC}$ and $\mathrm{FEF}_{75}$. Similar findings were reported in several studies in addition to the dose-response association. As, Alipour et al. ${ }^{19)}$ have suggested that ETS exposure may decline pulmonary function, as they found a significant difference in FVC and $\mathrm{FEV}_{1}$ between the exposed and non-exposed subjects. Also,
Chen et al. ${ }^{20)}$ reported a significant exposure-response relationship between ETS exposure in the workplace and lung function among never-smoking employees. Janson et al. ${ }^{14)}$ suggested a significant dose-related association between ETS exposure and $\mathrm{FEV}_{1}$ decline.

We found higher prevalence of BHR in ETS-exposed workers. As regards BHR categories, a significant relation was found with borderline BHR. Janson et al. ${ }^{9}$ reported similar findings, whereas in some previous studies significant association was not observed, i.e. increased bronchial responsiveness was found only in some studies ${ }^{21,22)}$.

The present study has several limitations. Passive smoking was only assessed through a questionnaire. Other more objective methods such as serum, salivary, or urine cotinine concentration should be the appropriate methods of choice.

For logistic reasons, our sample size was not adequately justified, and the design (cross-sectional) may not include people with serious respiratory diseases who had left their job, and the association between exposure and respiratory symptoms or diseases could be underestimated [healthy worker effect]. The findings suggest that passive smoking in the workplace can lead to respiratory symptoms, lung function impairment and increased bronchial responsiveness.

Implementation of control measures including the suitable legal or formal enforcement for banning smoking within workplaces should be addressed, which are in line with article 8 of the WHO Framework Convention on Tobacco Control that sets out recommendations for the development, implementation, and enforcement of national, comprehensive smoke-free laws, that can lead to improvements in the health of both workers who are occupationally exposed and of the general population.

\section{References}

1) Karjalainen A, Martikainen R, Karjalainen J, Klaukka T, Kurppa K (2002) Excess incidence of asthma among Finnish cleaners employed in different industries. Eur Respir J 19, 90-5. [Medline] [CrossRef]

2) Karjalainen A, Kurpa K, Martikainen R, Klaukka T, Karjalainen J (2001) Work is related to substantial portion of adult-onset asthma: incidence in Finnish population. Am J Respir Crit Care Med 164, 565-8. [Medline]

3) Medina-Ramón M, Zock JP, Kogevinas M, Sunyer J, Anto JM (2003) Asthma symptoms in women employed in domestic cleaning: a community-based study. Thorax $\mathbf{5 8}$, 950-4. [Medline] [CrossRef]

4) Thorn J, Brisman J, Tore K (2001) Adult-onset asthma 
is associated with self-reported mold or environmental tobacco smoke exposures in the home. Allergy 56, 287-92. [Medline] [CrossRef]

5) Carey IM, Cook DG, Strachan DP (1999) The effect of environmental tobacco smoke exposure on lung function in a longitudinal study of British adults. Epidemiology 10, 319-26. [Medline] [CrossRef]

6) Chan-Yeung M, Dimich-Ward H (2003) Respiratory health effects of exposure to environmental tobacco smoke. Respirology 8, 131-9. [Medline] [CrossRef]

7) Gilmour MI, Jaakkola MS, London SJ, Nel AE, Rogers CA (2006) How exposure to environmental tobacco smoke, outdoor air pollutants, and increased pollen burdens influences the incidence of asthma. Environ Health Perspect 114, 627-33. [Medline] [CrossRef]

8) Cacciola RR, Sarva M, Polosa R (2002) Adverse respiratory effects and allergic susceptibility in relation to particulate air pollutants: flirting with disaster. Allergy 57, 281-6. [Medline] [CrossRef]

9) Janson C, Chinn S, Jarvis D, Zock JP, Toren K, Burney P (2001) The European Community Respiratory Health Survey. Effects of passive smoking on respiratory symptoms, bronchial responsiveness, lung function, and total serum IgE in the European Community Respiratory Health Survey: a cross sectional study. Lancet 358, 2103-9. [Medline] [CrossRef]

10) American Thoracic Society (1995) Standardization of spirometry 1994 update. Am J Respir Crit Care Med 152, 1107-36. [Medline]

11) American Thoracic Society (2000) Guidelines for metacholine and exercise challenge testing - 1999. Am Respir Crit Care Med 161, 309-29.

12) Nielsen $H$ (1994) Occupational exposure to isothiazolinones: a study based on a product register. Contact Dermatitis 31, 18-21. [Medline] [CrossRef]

13) Zock JP, Kogevinas M, Sunyer J, Almar E, Muniozguren N, Payo F, Sanchez JL, Anto JM (2001) The Spanish working group of the European Respiratory Health Survey. Asthma risk, cleaning activities and use of specific cleaning products among Spanish indoor cleaners. Scand J Work
Environ Health 27, 76-81. [Medline] [CrossRef]

14) Karadžinska-Bislimovska J, Minov J, Risteska-Kuc S, Stoleski S, Mijakoski D (2007) Bronchial hyperresponsiveness in women cooks and cleaners. Arh Hig Rada Toksikol 58, 223-31. [Medline] [CrossRef]

15) Mijakoski D, Karadzinska-Bislimovska J, Minov J, Trajceva L, Ezova N, Risteska-Kuc S, Stoleski S (2007) Nasal symptoms in female cleaners: relation to respiratory symptoms, bronchial hyper-responsiveness, and duration of exposure. Eur Respir J 30, 154.

16) Ho SY, Lam TH, Chung SF, Lam TP (2007) Cross-sectional and prospective associations between passive smoking and respiratory symptoms at the workplace. Ann Epidemiol 17, 126-31. [Medline] [CrossRef]

17) Simoni M, Baldacci S, Puntoni R, FarchiS, Lo PrestiE, Pistelli R, Corbo G, Agabiti N, Basso S, Matteelli G, Di Pede F, Carrozzi L, Forastiere F, Viegi G (2007) Respiratory symptoms/diseases and environmental tobacco smoke (ETS) in never smoker Italian women. Respir Med 101, 531-8. [Medline] [CrossRef]

18) Lam TH, Ho LM, Hedley AJ, Peymane A, Fielding R, McGhee S, Aharonson-Daniel L (2000) Environmental tobacco smoke exposure among police officers in Hong Kong. JAMA 284, 756-63. [Medline] [CrossRef]

19) Alipour S, Deschamps F, Lesage FX (2006) Effects of environmental tobacco smoke on respiratory symptoms and pulmonary function. Inhal Toxicol 18, 569-73. [Medline] [CrossRef]

20) Chen R, Tunstall-Pedoe H, Tavendale R (2001) Environmental tobacco smoke and lung function in employees who never smoked: The Scottish MONICA study. Occup Environ Med 58, 563-8. [Medline] [CrossRef]

21) Stankus RP, Menon PK, Rando RJ, Glindmeyer H, Salvaggio JE, Lehrer SB (1988) Cigarette-smoke sensitive asthma: challenge studies. J Allergy Clin Immunol 82, 331-8. [Medline] [CrossRef]

22) Menon P, Rando RJ, Stankus RP, Salvaggio JE, Lehrer SB (1992) Passive cigarette smoke-challenge studies: increase in bronchial hyperreactivity. J Allergy Clin Immunol 89, 560-6. [Medline] [CrossRef] 